\title{
ТОВАРОВЕДНАЯ ХАРАКТЕРИСТИКА
}

\section{ПАНТОГЕМАТОГЕНА И ЕГО ЗНАЧЕНИЕ ПРИ АДАПТАЦИИ К ФИЗИЧЕСКИМ НАГРУЗКАМ}

\author{
Н.И. Суслов ${ }^{1}$, Н.Ю. Латков ${ }^{2}$, С.А. Трубчанинов ${ }^{2}$, В.М. Позняковский \\ ${ }^{1}$ НИИ фрармакологии Томского научного чентра СО РАН, г. Томск \\ ${ }^{2}$ Технологический институт пищевой промышленности (университет), г. Кемерово \\ ${ }^{3}$ Сочинский государственный университет, г. Сочи
}

\begin{abstract}
Дана товароведная характеристика биологически активной добавки «Пантогематоген» путем изучения химического состава, потребительских свойств и определения регламентируемых показателей качества. Препарат содержит значительный спектр биологически активных веществ, являющихся регуляторами важнейших метаболических функций и обладающих, соответственно, направленными функциональными свойствами. Подлинность пантогематогена подтверждена спектрофотометрически по содержанию гемоглобина. Представлены доказательные материалы натурных исследований на репрезентативной группе спортсменов по оценке эффективности и функциональной направленности разработанного продукта. В клинических испытаниях принимали участие высококвалифицированные гребцы-академисты, которые получали дополнительно к рациону в течение 14 дней пантогематоген по 0,4 г дважды в день до еды. Изучали работоспособность в различных стадиях утомления, динамику калиперометрических показателей и функциональное состояние организма. Сделано заключение о положительном влиянии диетотерапии на переносимость физических нагрузок гликолитической и смешанной направленности на фоне высокой степени адаптации мышечной массы. Специализированный продукт может быть рекомендован в качестве эффективной диетотерапии для повышения работоспособности спортсменов циклических видов спорта. Функциональная направленность и отсутствие допингового влияния подтверждены экспертным заключением Государственной санитарно-эпидемиологической службы Российской Федерации, Головного испытательного центра пищевой продукции при ГУ НИИ питания РАМН.

Ключевые слова: биологически активная добавка, характеристика, высококвалифицированные спортсмены, клинические испытания, эффективность, функциональная направленность.
\end{abstract}

Товароведная оценка специализированных продуктов, в том числе биологически активных добавок (БАД) для спортивного питания, подразумевает проведение исследований химического состава, характеристику действующих начал рецептурных компонентов, а также проведение клинических испытаний в качестве приоритетных потребительских свойств $[1,3,5,8]$.

Разработан биологически активный комплекс - БАД «Пантогематоген». Представляет собой порошкообразное, аморфное вещество, полученное из свежей, частично дефибринированной, дегидратированной в мягких условиях крови пантового оленя (марала) и последующей сушкой и измельчением.

Технологический процесс дегидратации и измельчения проводится в глубоком вакууме (-1 атм), при щадящих температурных режимaх $\left(36-40{ }^{\circ} \mathrm{C}\right)$, что обеспечивает бактериологическую чистоту, высокую сохранность и функциональную активность.
Изучение химического состава выполнено на базе лаборатории фармакологии НИИ фармакологии Томского научного центра СО PAMH.

Биологически активные вещества представлены аминокислотами, липидными соединениями, главным образом, фосфолипидами (фосфатидилхолин, фосфатидилэтаноламин, холестерол), большим количеством микроэлементов. Содержание основных нутриентов представлено в табл. 1 (даны усредненные данные из трех определений шести однородных партий продукции).

Материалы, приведенные в табл. 1, показывают, что пантогематоген является источником целого ряда структурных и биологически активных веществ.

Некоторые из них можно рассматривать в качестве важнейших питательных субстратов, большая часть из которых представлена высокоактивными регуляторными молекулами (так называемыми сигнальными веществами). 
Химический состав пантогематогена

Таблица 1

\begin{tabular}{|c|c|c|c|}
\hline Вещества & Содержание, г/100 г & Вещества & Содержание, мг/100 г \\
\hline \multicolumn{2}{|l|}{ Аминокислоты } & Изолецитин & 0,143 \\
\hline Лизин & 0,9 & Лецитин & 0,233 \\
\hline Гистидин & 0,35 & Коламинкефалин & 0,358 \\
\hline Аргинин & 1,13 & Цереброзид & 0,483 \\
\hline 4-оксипролин & 0,95 & Кардиолипин & 0,555 \\
\hline Гистидин & 0,35 & \multicolumn{2}{|c|}{ Макро-, микроэлементы } \\
\hline Аргинин & 1,13 & Кальций & 0,15 \\
\hline 4-оксипролин & 0,95 & Магний & 74 \\
\hline Триптофан & 1,26 & Алюминий & 27 \\
\hline Треонин & 0,57 & Железо & 360 \\
\hline Серии & 0,68 & Кремний & 28 \\
\hline Глутаминовая & 1,6 & Фосфор & 120 \\
\hline Пролин & 1,27 & Натрии & 900 \\
\hline Глицин & 2,2 & Калии & 120 \\
\hline Алании & 1,38 & Медь & 0,1 \\
\hline Цистин & 0,04 & Йод & 0,08 \\
\hline Валин & 0,64 & Марганец & 34 \\
\hline Метионин & 0,1 & Олово & 3 \\
\hline Изолейцин & 0,24 & Барий & 6,4 \\
\hline Лейцин & 1,15 & Кобальт & 0,05 \\
\hline Тирозин & 0,24 & Ванадий & 0,04 \\
\hline Саркозин & 1,16 & \multirow{2}{*}{\multicolumn{2}{|c|}{ Основания нуклеиновых кислот }} \\
\hline Таурин & 0,03 & & \\
\hline \multicolumn{2}{|l|}{ Липиды } & Гуанин & 39,9 \\
\hline $\begin{array}{l}\text { Свободные жирные } \\
\text { кислоты }\end{array}$ & 0,56 & \multirow[t]{2}{*}{ Гипоксантин } & \multirow[t]{2}{*}{44,2} \\
\hline Фосфолипиды & 2,42 & & \\
\hline Триглицериды & 0,51 & \multirow{2}{*}{ Урацил } & \multirow{2}{*}{39,1} \\
\hline Сфингомиелин & 0,179 & & \\
\hline
\end{tabular}

Их поступление в организм даже в незначительных количествах запускает каскад метаболических реакций. Они могут влиять на каталитическую активность энзимов и аффинитет (чувствительность, сродство) распознающих белков [2, 4, 6, 7, 9-11].

Приведенные материалы говорят о том, что пантогематоген содержит широкий набор веществ, обладающих значительной биологической активностью, при этом многие из них являются регуляторами важнейших физиологических функций, обеспечивая его фармакологическую направленность.
Исследования потребительских свойств в процессе производства и хранения позволили определить регламентируемые органолептические и физико-химические показатели качества (табл. 2), а также пищевую и энергетическую ценность (табл. 3).

Получено экспертное заключение Государственной санитарно-эпидемиологической службы Российской Федерации, Головного испытательного центра пищевой продукции при ГУ НИИ питания РАМН, санитарноэпидемиологическое заключение. 
Регламентируемые показатели качества «Пантогематогена»

\begin{tabular}{|c|c|}
\hline Наименование показателя & Характеристика и норма \\
\hline Внешний вид & $\begin{array}{l}\text { Аморфный порошок от красновато-коричневого до } \\
\text { темно-коричневого цвета }\end{array}$ \\
\hline Запах & Специфический \\
\hline Вкус & Специфический с привкусом мяса \\
\hline Дисперсность & $\begin{array}{l}\text { Частицы с диаметром более } 0,63 \text { мм - не более } 2 \% \text {. } \\
\text { Частицы диаметром более } 2 \text { мм - отсутствуют }\end{array}$ \\
\hline Влажность & Не более $9 \%$ \\
\hline $\begin{array}{l}\text { Подлинность: по спектру поглощения } \\
\text { гемоглобина раствора добавки в } 0,5 \% \\
\text { растворе аммиака }\end{array}$ & $\begin{array}{l}\text { В диапазоне от } 480 \text { до } 650 \text { нМ должен определяться } \\
\text { двойной сглаженный пик с максимумами поглоще- } \\
\text { ния при }(540 \pm 10) \text { нМ и }(570 \pm 10) \text { нМ }\end{array}$ \\
\hline $\begin{array}{l}\text { Количественное содержание пантогема- } \\
\text { тогена определяется спектрофотометри- } \\
\text { чески по содержанию гемоглобина }\end{array}$ & $\begin{array}{l}\text { При исследовании на спектрофотометре раствора } 0,1 \\
\text { г добавки (точная навеска) в } 0,5 \% \text { раствора аммиа- } \\
\text { ка, доведенном до } 50 \text { см}^{3} \text { при } 540 \text { нМ, оптическая } \\
\text { плотность раствора не менее } 0,4\end{array}$ \\
\hline
\end{tabular}

Таблица 3

Пищевая и энергетическая ценность «Пантогематогена»

\begin{tabular}{|l|c|}
\hline \multicolumn{1}{|c|}{ Наименование показателя, г/100 г } & Значение \\
\hline Белки и аминокислоты & $96,0-97,0(96,5)$ \\
\hline Углеводы & $0,16-0,18(0,17)$ \\
\hline Жиры & $0,05-0,07(0,06)$ \\
\hline Энергетическая ценность, ккал/100 г & $385-389(387)$ \\
\hline
\end{tabular}

Примечание: В скобках даны усредненные значения из 6-ти определений.

В клинических испытаниях принимали участие гребцы-академисты в количестве 12 человек (8 мужчин и 4 женщины) в возрасте 21-34 лет, имеющие квалификацию мастера спорта, мастера спорта международного класса, заслуженного мастера спорта. Были сформированы две группы: первая контрольная, вторая - основная по 6 человек (4 мужчины и 2 женщины). Стаж занятий спортом от 7 до 19 лет.

Все спортсмены в течение 3-х недель находились на учебно-тренировочном сборе в одинаковых условиях питания, нагрузок и восстановления под постоянным медицинским наблюдением.

Испытуемые основной группы ежедневного получали дополнительно к рациону в течение 14 дней пантогематоген по 0,4 г дважды в день до еды. Спортсмены контрольной группы - плацебо (оротат калия) по аналогичной схеме.
До начала курса приема пантогематогена и после его окончания проводилось тестирование, поэтапное медицинское обследование и анкетирование.

Для оценки количественных показателей скорости и функционального состояния организма использовали тест ступенчато возрастающей нагрузки на гребном эргометре «Хессинг» с параллельным контролем уровня молочной кислоты в периферической крови. Врачебный контроль включал регистрацию артериального давления, частоту сердечных сокращений (ЧЧС), электрокардиограмму (ЭКГ) и калиперометрический анализ изменения состава тела.

Самооценка функционального состояния спортсменов осуществлялась с помощью анкетирования.

Получены материалы по влиянию пантогематогена на показатели работоспособности гребцов (см. рисунок). Двухнедельный прием 
препарата способствовал сокращению времени выполнения работы на фиксированных этапах ступенчатого теста при одновременном снижении концентрации лактата в периферической крови. Для испытуемых основной группы прирост скорости при уровнях лактата 2, 4 и 6 ммоль/л составил соответственно 14,3, 7,2 и 4,5 cм/c (p < 0,05). При значении лактата 8 ммоль/л отмечена статистически недостоверная тенденция к увеличению скорости. В контрольной группе достоверное повышение скорости наблюдалось только при концентрациях молочной кислоты 2 и 4 мМ/л и составляло 13,1 и $5,3 \mathrm{~cm} / \mathrm{c}$, что ниже соответствующих значений в основной группе. При более высоких показателях лактата 9,6 и 8 ммоль/л скорость выполнения работы на фиксированных отрезках у спортсменов контрольной группы достоверно снижалась ( $<0,05)$.

Таким образом, спортсмены, получавшие дополнительно к рациону пантогематоген, были способны увеличивать скорость выполнения работы даже при концентрациях лактата 6 и 8 ммоль/л, тогда как в контрольной группе уже при концентрации молочной кислоты 6 ммоль/л отмечалось снижение работоспособности.

Из результатов проведенного исходного и повторного (через 14 дней) тестов ступенчато возрастающей нагрузки следует, что уровень молочной кислоты максимально снижался в группе обследуемых, принимавших пантогематоген. Достоверное снижение лактата на 1й и 3-й ступенях теста составляло соответственно 33 и $9 \%(\mathrm{p}<0,05)$. На остальных ступенях отмечена тенденция к снижению данного показателя. В отличие от основной, у спорт- сменов контрольной группы, при повторном тестировании, не обнаружено достоверного снижения молочной кислоты. Сделано заключение, что 2-недельный прием биологически активной добавки «Пантогематоген сухой» приводит к улучшению биохимических показателей крови, повышению скорости выполняемой работы на фиксированных периодах, характеризующих также мощность работы при общей экономии энергозатрат. Большое значение имеет увеличение доли жирового обмена в производстве энергии на нужды мышечной деятельности и сокращение использования мышечного белка и аминокислот в этих целях.

Изучено влияние препарата на состав тела путем анализа динамики калиперометрических показателей у гребцов основной и контрольной групп (табл. 4, 5). Все спортсмены находились на заключительном тренировочном сборе перед летним чемпионатом России по гребле. В связи с этим характер нагрузок носил преимущественно гликолитическое направление, что подтверждает динамика соотношения регистируемых показателей у спортсменов контрольной группы.

В основной группе, при сохранении мышечной массы тела, объем жировой ткани достоверно уменьшился. Этот факт позволяет говорить о том, что курсовое применение пантогематогена, в течении тренировочного сбора, способствует сохранению мышечной массы гребцов, препятствуя ее падению на фоне гликолитических нагрузок за счет вовлечения дополнительного количества жиров в энергетический обмен.

Сопоставляя данные калиперометриче-

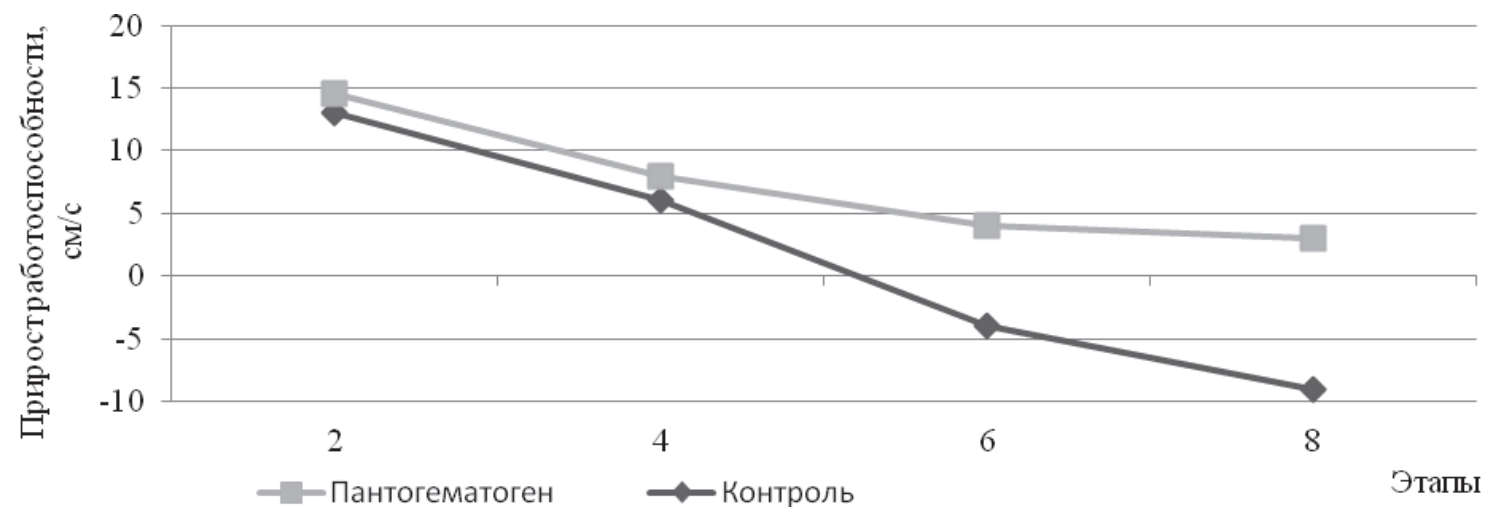

Влияние пантогематогена на работоспособность спортсменов-гребцов в различных стадиях утомления 
Динамика калиперометрических показателей состава тела гребцов основной группы

\begin{tabular}{|c|c|c|c|c|}
\hline \multirow{2}{*}{$№$ п/п } & \multicolumn{2}{|c|}{ Исходное тестирование } & \multicolumn{2}{c|}{ Повторное тестирование } \\
\cline { 2 - 5 } & МТ (кг) & ММ/МЖ (\%) & МТ (кг) & ММ/МЖ (\%) \\
\hline 1 & 82,0 & $55,2 / 9,7$ & 81,8 & $55,4 / 9,1$ \\
\hline 2 & 80,1 & $53,9 / 11,4$ & 80,4 & $54,0 / 11,3$ \\
\hline 3 & 76,4 & $55,9 / 8,6$ & 76,9 & $55,6 / 8,8$ \\
\hline 4 & 79,3 & $51,4 / 7,9$ & 79,3 & $51,2 / 7,5$ \\
\hline 5 & 76,2 & $49,8 / 13,3$ & 76,9 & $51,0 / 13,0$ \\
\hline 6 & 75,2 & $52,0 / 11,8$ & 74,3 & $52,9 / 10,9$ \\
\hline & 78,13 & $53,12 / 10,45$ & 78,3 & $53,28 / 10,05$ \\
\hline
\end{tabular}

Таблица 5

Динамика калиперометрических показателей состава тела гребцов контрольной группы

\begin{tabular}{|c|c|c|c|c|}
\hline \multirow{2}{*}{$№$ п/п } & \multicolumn{2}{|c|}{ Исходное тестирование } & \multicolumn{2}{c|}{ Повторное тестирование } \\
\cline { 2 - 5 } & МТ (кг) & ММ/МЖ (\%) & МТ (кг) & ММ/МЖ (\%) \\
\hline 1 & 84,3 & $56,5 / 9,9$ & 84,0 & $55,9 / 9,4$ \\
\hline 2 & 85,1 & $54, / 10,8$ & 84,6 & $53,7 / 10,2$ \\
\hline 3 & 79,4 & $52,5 / 8,5$ & 79,2 & $52,0 / 8,8$ \\
\hline 4 & 73,8 & $55,9 / 8,9$ & 73,4 & $55,2 / 8,5$ \\
\hline 5 & 71,7 & $52,1 / 12,8$ & 72,0 & $51,7 / 12,9$ \\
\hline 6 & 76,6 & $53,9 / 10,8$ & 76,5 & $54,0 / 11,4$ \\
\hline & 78,48 & $54,18 / 10,18$ & 78,28 & $53,7 / 10,26$ \\
\hline
\end{tabular}

ского обследования спортсменов с результатами тестирования работоспособности можно заключить, что экономизация энергозатрат у гребцов, принимавших БАД, связана с более высоким уровнем адаптации к нагрузкам мышечной массы в этой группе обследуемых.

Сделан анализ медицинского контроля состояния спортсменов и данных анкетирования. Закономерности, обнаруженные при исследовании влияния пантогематогена на показатели работоспособности гребцов и состава тела, нашли подтверждение в результатах самооценки состояния спортсменов методом анкетирования. Все гребцы из основной группы отмечали нормальную переносимость нагрузок, желание тренироваться, отсутствие каких-либо нарушений сна и аппетита. В тоже время 3 спортсмена из контрольной группы отмечали ухудшение сна и нарастание усталости к концу сбора.

Медицинский контроль за время прове- дения эксперимента не выявил существенных отклонений от нормы, за исключением признаков перенапряжения миокарда у 2-х гребцов контрольной группы к последнему микроциклу сбора.

Каких-либо побочных эффектов при применении препарата, по данным опроса гребцов и объективного медицинского контроля, не выявлено.

Проведенные испытания «Пантогематоген сухой» позволяют заключить, что использование БАД при курсовом приеме оказывает положительное влияние на переносимость нагрузок гликолитической и смешанной направленности, вызывая сдвиг лактатной кривой вправо. При этом удается сохранить более высокую степень адаптации мышечной массы к тренировочным нагрузкам $[12,13]$.

Пантогематоген может быть рекомендован в качестве эффективного недопингового средства повышения специальной работоспо- 
собности спортсменов циклических видов спорта на заключительном этапе подготовки с преимущественно гликолитической и смешанной направленностью нагрузок.

\section{Литература}

1. Биохимические основы физической работоспособности: учебное пособие / coсm. Л.Н. Тюрина. - Омск: СибГУФК, 2003. - 80 с.

2. Гичев, Ю.Ю. Новое руководство по микронутриентологии (биологически активные добавки к пище и здоровье человека) / Ю.Ю. Гичев. - М.: Триада-Х, 2009. - 304 c.

3. Калинин, В.М. Актуальные вопросы питания: витаминь и минеральные вещества при занятиях физической культурой и спортом: монография / В.М. Калинин, В.М. Позняковский; - Томск: Изд-во Томского государственного педагогического университета, 2008. -160 c.

4. Кулиненков, О.С. Фармакология спорта: Клинико-физиологический справочник спорта высших достижений / О.С. Кулиненков. - 3-е изд., перераб. и доп. - М.: Советский спорт, 2001. $-200 \mathrm{c}$.

5. Латков, Н.Ю. Макро- и микронутриенты в питании спортсменов: монография / Н.Ю. Латков, В.М. Позняковский. - Кемерово: Кемеровский технологический институт пищевой промышленности, 2011. - 172 с.

6. Михайлов С.С. Спортивная биохимия: Учебник для вузов и колледжей физической культуры. - 2-е изд., доп. - М.: Советский cnopm, 2004. - 220 c.

7. Позняковский, В.М. Пищуевые и биоло- гически активные добавки: характеристика, применение, контроль: монография / В.М. Позняковский, Ю.Г. Гурьянов, В.В. Бебенин. - 3-е изд., испр. и доп. - Кемерово: Кузбассвузизdam, 2011. - 275 c.

8. Покровский, А.А. Метаболистические аспекты фармакологии и токсикологии пищи. - М.: Медицина, 1979. - 184 c.

9. Суслов, Н.И. Продукичия на основе пантогематогена. Механизмы действия и особенности применения: монография / Н.И. Суслов, Ю.Г. Гурьянов. - Новосибирск: Сибирское университетское издательство, 2004. $144 c$.

10. Тутельян, В.А. Современное состояние и перспективы развития науки о питании / В.А. Тутельян, В.М. Позняковский // Современные приоритеть питания, пищевой промылиленности и торговли: сб. научн. трудов, посвященных юбилею кафедры биотехнологии, товароведения и управления качеством / под общ. ред. В.М. Позняковского. - М.; Кемерово: Издательское объединение «Российские университеты»: "АСТШ: Кузбассвузиздат», 2006. - C. 5-10.

11. Williams, M.H. Nutritional Ergogenic Aids / M.H. Williams, B.C. Leutholtz // Nutrition in Sport. - 2000. - P. 356-366.

12. Ivy J/L/ Optimization of Glycogen Stores // Nutrition in Sport / Maughan R.M. (Ed). Blackweii Science Ltd., 2000. - P. 97-111.

13. Hespel, P. Dietary supplements for football / P. Hespel, R.J. Maughan, P.L. Greenhaff // Journal of Sports Sciences. - 2006. - 24(7). P. 749-761.

Суслов Николай Иннокентьевич. Заведующий лабораторией фитофармакологии и специализированного питания, доктор медицинских наук, профессор, НИИ фармакологии Томского научного центра СО РАН (г. Томск).

Латков Николай Юрьевич. Докторант кафедры товароведения и управления качеством, кандидат технических наук, Кемеровский технологический институт пищевой промышленности (университет) (г. Кемерово), nlatkov@yandex.ru.

Трубчанинов Сергей Анатольевич. Аспират кафедры товароведения и управления качеством, Кемеровский технологический институт пищевой промышленности (университет) (г. Кемерово).

Позняковский Валерий Михайлович. Доктор биологических наук, Заслуженный деятель науки РФ, профессор, руководитель научно-образовательного центра здорового питания и индустриальных технологий, профессор кафедры «Гостиничный и ресторанный бизнес», Сочинский государственный университет (г. Сочи), poznyakovskiy48@bk.ru

Поступила в редакциию 5 мая 2016 2. 


\title{
MERCHANDIZING CHARACTERISTIC OF PANTO-HEMATOGEN AND ITS SIGNIFICANCE DURING THE ADAPTATION TO PHYSICAL LOADS
}

\author{
N.I. Suslov', N.Yu. Latkov', S.A. Trubchaninov ${ }^{2}$, V.M. Poznyakovsky ${ }^{3}$ \\ ${ }^{1}$ Research Institute of Pharmacology of Tomsk Scientific Center SB RAS, Tomsk, \\ Russian Federation \\ ${ }^{2}$ Kemerovo Institute of Food Science and Technology (University), Kemerovo, \\ Russian Federation \\ ${ }^{3}$ Sochi State University, Sochi, Russian Federation
}

\begin{abstract}
Merchandizing characteristic of biologically active additive "Panto-hematogen" is given by studying the chemical composition, consumer properties and determining regulated quality indicators. The product contains a considerable range of biologically active substances, which are regulators of the most important metabolic functions and which, accordingly, have directed functional properties. Authenticity of panto-hematogen is confirmed spectrophotometrically by the hemoglobin content. Evidentiary materials of full-scale investigations based on a representative group of athletes on the evaluation of efficacy and functional orientation of the developed product are presented. Highly qualified oarsmen-academics took part in clinical trials. Additionally to their diet they took 0.4 grams of panto-hematogen twice a day before meal during 14 days. The performance in various stages of tiredness, dynamics of caliperometric indicators and functional state of the organism are studied. The conclusion is made on the positive effect of diet therapy on the exercise tolerance of glycolytic and mixed focus on the background of a high degree of adaptation of muscle bulk. The specialized product can be recommended as an effective diet therapy to improve the performance of sportsmen of cyclic sports. Functional orientation and the absence of doping influence are proved by the expert report of the State Sanitary and Epidemiological Service of the Russian Federation, the Head Test Center for Food Products at the Research Institute of Nutrition of the Russian Academy of Medical Sciences.
\end{abstract}

Keywords: biologically active additives, characteristics, highly qualified sportsmen, clinical trials, effectiveness, functional orientation.

\section{References}

1. Tyurina L.N. Biokhimicheskie osnovy fizicheskoy rabotosposobnosti [Biochemical bases of physical efficiency]. Omsk, 2003. 80 p.

2. Gichev Yu.Yu. Novoe rukovodstvo po mikronutrientologii (biologicheski aktivnye dobavki $k$ pishche $i$ zdorov'e cheloveka) [New guidance on micro nutrition studies (food biologically active additives and human health)]. Moscow, 2009. 304 p.

3. Kalinin V.M., Poznyakovskiy V.M. Aktual'nye voprosy pitaniya: vitaminy i mineral'nye veshchestva pri zanyatiyakh fizicheskoy kul'turoy i sportom [Topical issues on nutrition: vitamins and minerals when doing physical exercises and sports]. Tomsk, 2008. 160 p.

4. Kulinenkov O.S. Farmakologiya sporta: Kliniko-fiziologicheskiy spravochnik sporta vysshikh dostizheniy [Pharmacology of sport: Clinical and physiological reference book of sport of high performance]. 3nd ed. Moscow, Sovetskiy sport Publ., 2001. 200 p.

5. Latkov N.Yu., Poznyakovskiy V.M. Makro- $i$ mikronutrienty v pitanii sportsmenov: Monografiya [Macro and micronutrients in the diet of athletes]. Kemerovo, 2011.172 p.

6. Mikhaylov S.S. Sportivnaya biokhimiya [Sport biochemistry]. 2nd ed. Moscow, Sovetskiy sport Publ., 2004. 220 p.

7. Poznyakovskiy V.M., Gur'yanov Yu.G., Bebenin V.V. Pishchevye i biologicheski aktivnye dobavki: kharakteristika, primenenie, kontrol' [Food additives and biologically active additives: characteristics, application, control]. 3nd ed. Kemerovo, Kuzbassvuzizdat, 2011. 275 p.

8. Pokrovskiy A.A. Metabolisticheskie aspekty farmakologii i toksikologii pishchi [Metabolic aspects of the pharmacology and toxicology of food]. Moscow, Meditsina, 1979. 184 p.

9. Suslov N.I., Gur'yanov Yu.G. Produktsiya na osnove pantogematogena. Mekhanizmy deystviya i osobennosti primeneniya [Products based on panto-hematogen. Mechanisms of action and application peculiarities]. Novosibirsk, Sibirskoe universitetskoe izdatel'stvo, 2004. 144 p. 
10. Tutel'yan V.A., Poznyakovskiy V.M. [The current state and prospects of development of the science of nutrition]. Sovremennye prioritety pitaniya, pishchevoy promyshlennosti i torgovli: sb. nauchn. trudov, posvyashchennykh yubileyu kafedry biotekhnologii, tovarovedeniya i upravleniya kachestvom [Modern trends in nutrition, food industry and trade: collection of research papers devoted to the anniversary of the Department of Biotechnology, Commodity Research and Quality Control]. Moscow, Kemerovo, 2006, pp. 5-10. (in Russ.)

11. Williams M.H., Leutholtz B.C. Nutritional Ergogenic Aids. Nutrition in Sport, 2000, pp. 356-366. DOI: 10.1002/9780470693766.ch26

12. Ivy J.L. Optimization of Glycogen Stores. Nutrition in Sport. Blackweii Science Ltd., 2000, pp. 97-111.

13. Hespel P., Maughan R.J., Greenhaff P.L. Dietary supplements for football. Journal of Sports Sciences, 2006, 24(7), pp. 749-761. DOI: 10.1080/02640410500482974

Nikolay I. Suslov. Head of the Laboratory of Phytopharmacology and Specialized Nutrition, Doctor of Sciences (Medicine), Professor, Research Institute of Pharmacology of Tomsk Scientific Center SB RAS (Tomsk).

Nikolay Yu. Latkov. Doctoral Candidate of the Department of Commodity Research and Quality Management, Candidate of Sciences (Engineering), Kemerovo Institute of Food Science and Technollogy (University) (Kemerovo),nlatkov@yandex.ru.

Sergey A. Trubchaninov. PhD student of the Department of Commodity Research and Quality Management, Kemerovo Institute of Food Science and Technology (University) (Kemerovo).

Valery M. Poznyakovsky. Doctor of Sciences (Biology), honored scientist of the Russian Federation, Professor, Head of the Scientific and Educational Center for Healthy Nutrition and Industrial Technology, Professor of the Department of Hotel and Restaurant Business, Sochi State University (Sochi), poznyakovskiy48@bk.ru

Received 5 May 2016

\section{ОБРАЗЕЩ ЦИТИРОВАНИЯ}

Товароведная характеристика пантогематогена и его значение при адаптации к физическим нагрузкам / Н.И. Суслов, Н.Ю. Латков, С.А. Трубчанинов, В.М. Позняковский // Вестник ЮУрГУ. Серия «Пищевые и биотехнологии». - 2016. - Т. 4, № 2. - С. 86-93. DOI: $10.14529 /$ food 160211

\section{FOR CITATION}

Suslov N.I., Latkov N.Yu., Trubchaninov S.A., Poznyakovsky V.M. Merchandizing Characteristic of PantoHematogen and its Significance During the Adaptation to Physical Loads. Bulletin of the South Ural State University. Ser. Food and Biotechnology, 2016, vol. 4, no. 2, pp. 86-93. (in Russ.) DOI: 10.14529/food160211 